\title{
Faulty Weaning Practices among Infants in Suez Canal Area and its Complications
}

\author{
Suzan S. Gad, Amany M. Elkelany, Shaimaa A. Abdel-Meged ${ }^{*}$
}

Department of Pediatrics, Faculty of Medicine, Suez Canal University, Egypt

\begin{abstract}
Background: Faulty Complementary feeding (CF) is a worldwide problem that increases risk of malnutrition, gastrointestinal, respiratory illness, childhood obesity, allergic manifestation, and immune system disorders. Aim: to investigate the impact of faulty practices of complementary feeding on growth parameters, and to focus on the common adverse effect. Subjects and Methods: Our study is a cross sectional study that was carried out in Outpatient Clinics of Pediatrics at hospitals and health care units in Suez Canal area. A well-designed Questionnaire was done to show the pattern of CF of 418 infants below 2 years selected in sequence. Infants with positive family history of allergy, congenital anomalies, debilitating systemic disease and infants under treatment were excluded from the study. We made a 20 minutes interviews with mothers of included infants to answer questionnaire about the dietetic history. Anthropometric measures and full examination was done for every infant. Results: Our results showed that the incidence of faulty CF was (58.7\%), mothers who introduced complementary feeding before 4 months was $(47.5 \%)$, their infants were more exposed to gastrointestinal illness (52.2\%), respiratory illness (76\%), eczema (51.8\%) and mouth ulcers $(74.6 \%)$, than infants who started CF at the age 4-6months and after 6 months. Infants who started CF after 6 months were more exposed to be underweight (43.2\%)and to have manifestations of pallor and vitamin $D$ deficiency (37\%). Conclusion: Introduction of food before 4 months leads to significant high incidence of gastrointestinal illness, eczema, respiratory illness, mouth ulcer, and obesity while, introduction of food after $6 \mathrm{months}$ lead to the risk of underweight and manifestations of pallor and vitamin $D$ deficiency.
\end{abstract}

Keywords: complementary feeding, growth, infectious disease, allergic manifestations

\section{Introduction}

The introduction to solid feeding and gradual replacement of milk by solid food as the main source of nutrition is the process known as complementary feeding. WHO recommended that mothers should breast feed their children exclusively for six months of life to protect against allergic manifestation, diarrhea and respiratory tract infection $^{(1)}$. In its recent publications WHO issued a statement, referring to a Cochrane meta analysis suggests that exclusive breastfeeding for 6 months shows a deficit in weight and length gain and compromise hematological status of infants. So, recommended that infants be exclusively breastfed for 4-6 months as delay weaning until 6 months of age, will expose infants to growth and nutritional deficiency versus the risks of infection, associated with earlier complementary feeding ${ }^{(2)}$. In developing countries, introduction of solid food early increase risk of gastrointestinal infection due to contamination of food. Early aggressive complementary feeding or excess sugary food leads to colic and constipation. Sudden feeding on starchy food lead to Kwa- 
shiorkor ${ }^{(3)}$. Sufficient volume of breast milk from a well nourished mother should supply the nutrient needs of the infant until 6 months of age except vitamin D, zinc, iron and other micronutrients. So complementary feeding should be at 4-6 months of age in a gradual process with special needs of groups as low birth weight (LBW) or preterm infants ${ }^{(3)}$. Protein energy malnutrition and micro-nutrient under-nutrition occur together, 10 million children under the age of 5 years old die each year. More than half of the deaths occur because of malnutrition. Nearly $2 / 3$ of the deaths could be prevented by managing strategies to optimize nutritional status ${ }^{(4)}$. The suggested allergy preventing effect of exclusive breastfeeding may be due to a reduced exposure to dietary antigens, immunologically active factors in human milk extending from mothers to infant during first months of life ${ }^{(5)}$. Due to deficiency of researches in Suez Canal area about the faults associated with complementary feeding, we organized this study.

\section{Subjects and Methods}

The study was a cross sectional study, carried out in Outpatient Clinics of Pediatrics including General Suez hospital, Suez Canal University hospital, General Port Said Hospital and health care units in Suez Canal area. It included 418 infants below the age of two years selected in sequence from selected sites.

\section{Subjects}

Simple random method was used. Sample included all infants below age of two years. Infants with positive family history of allergy, infants with major congenital anomalies, debilitating systemic disease, or Infants of special feeding formula as treatment were excluded. We made 20 minutes interview with mothers of included infants to answer questionnaire. A pilot study to evaluate the ques- tionnaire was conducted on 100 selected infants less than two years from selected sits. The pilot study demonstrated that the methods and procedures are valid.

\section{Methods}

All mothers were asked about: i) personal history (age, sex, residence, order of birth, occupation, socioeconomic status, consanguinity, and income), ii) -Vaccination and medication history, iii) past history of disease, iv) Full dietetic history (type of milk, age of weaning, type of weaning, type of food which was first introduced to the infants and its reaction to it ), v) Allergic manifestations (respiratory; persistent cough and wheezes, skin; atopic dermatitis with typical itchy papulovesicular rash in face, neck and extremities that is chronic and relieved by topical steroids, and mouth ulcer), vi) Any gastrointestinal tract manifestations (vomiting, constipation, diarrhea, abdominal distension, streaks of blood in stool). All infants were subjected to general examination and anthropometric measures (weight/age, length/age, head circumference and chest/ head circumference ratio) and were put on Egyptian percentile (underweight, short stature, small head who are below $5^{\text {th }}$ percentile but overweight, tall stature, large head who are above $95^{\text {th }}$ percentile

\section{Results}

Most of studied infants (43.3\%) aged 7-12

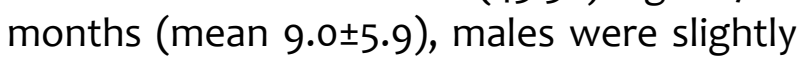
more than females ( $56.2 \%$ vs. $43.8 \%$, respectively) (Table 1). We found that $47.5 \%$ of the mothers started complementary feeding before 4 months while, $11.2 \%$ exclusively breastfed till 6 months. Concerning type of food started with $22.2 \%$ of mothers began with yoghurt and cow milk (Table 2 ). Infants fed on breast-feeding represented $45.7 \%$ while $12.7 \%$ used formula feeding, $32.3 \%$ used cow milk, and 9.3\% used mixed feeding (Figure 1). 
Table 1: Socio-demographic characteristics of the studied infants $(n=418)$

\begin{tabular}{|c|c|}
\hline $\begin{array}{l}\text { Age (months) } \\
\text { Mean } \pm \text { SD } \\
\text { Range }\end{array}$ & $\begin{array}{l}9.02 \pm 5.9 \\
1-24\end{array}$ \\
\hline $\begin{array}{l}\text { Age groups No (\%) } \\
\leq 6 \text { months } \\
7-12 \text { months } \\
13-18 \text { months } \\
19-24 \text { months }\end{array}$ & $\begin{array}{l}147(35.2) \\
181(43.3) \\
66(15.8) \\
24(5.7)\end{array}$ \\
\hline $\begin{array}{l}\text { Gender } \\
\text { Male } \\
\text { Female }\end{array}$ & $\begin{array}{l}235(56.2) \\
183(43.8)\end{array}$ \\
\hline
\end{tabular}

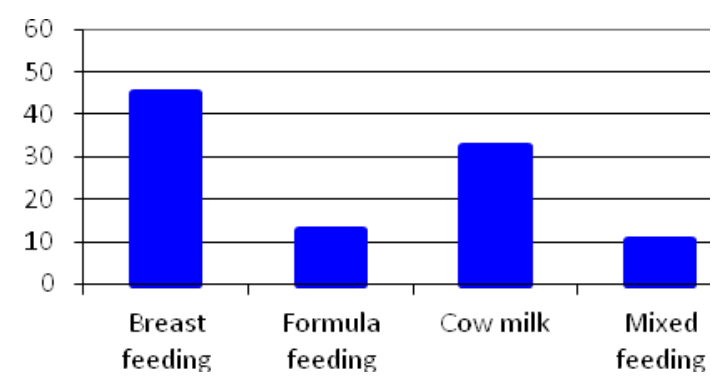

Figure 1: Type of milk given among the studied infants

We found that $69.7 \%$ of the infants eat adequate amount of food, $24.2 \%$ of them eat limited variety of specific food, and $75.8 \%$ eat unlimited variety of specific food. Vomiting was the most common cause of inadequate feeding among the studied infants (Tables 4). The main cause of early complementary feeding before 4 months was the community thoughts to prepare their infants to eat on ordinary food as adults (38\%) followed by working mothers $(27.3 \%)$ as in (Table 5). The prevalence of studied infants who were underweight was (8.9\%) of total population, most of them of underweighted were complementary fed after 6 months (43.2\%). The prevalence of studied infant who were overweight was (3.5\%) of total population, most of them were complementary fed before 4months $(66.7 \%)$ as in (Table 6). The prevalence of gastrointestinal illness in studied infants was $65 \%$; the majority of infants who started complementary feeding <4months of age represented $52.2 \%$ of infants who had gastrointestinal illness, (group 1 vs. group 2, $p=0.004$ ), (group 2 vs. group $3, p=0.004$ ) and (group 1 vs. group $3, p=0.001$ ).

Table 2: Characteristics of complementary feeding practices among the studied infants $(\mathrm{n}=356)$

\begin{tabular}{|c|c|}
\hline $\begin{array}{l}\text { Onset of complementary feeding } \\
\text { no }(\%) \\
\qquad \begin{array}{l}<4 \text { months } \\
4-6 \text { months } \\
>6 \text { months }\end{array}\end{array}$ & $\begin{array}{c}169(47.5) \\
147(41.3) \\
40(11.2)\end{array}$ \\
\hline 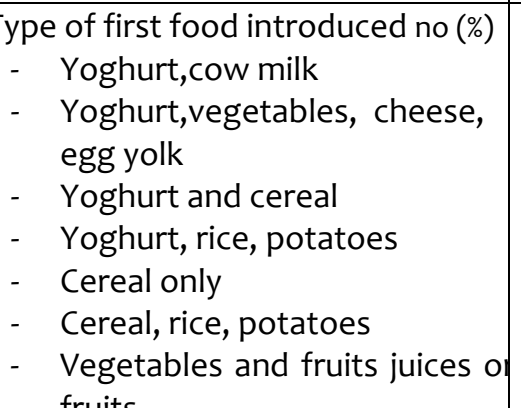 & $\begin{array}{l}79(22.2) \\
77(21.6) \\
52(14.6) \\
31(8.7) \\
23(6.5) \\
61(17.1) \\
33(9.3)\end{array}$ \\
\hline
\end{tabular}

Table 3: Feeding practices and causes of inade quate feeding of the studied infants

\begin{tabular}{|l|l|}
\hline $\begin{array}{l}\text { Infant eat adequate } \\
\text { amount of food } \\
\text { No }\end{array}$ & $108(30.3)$ \\
Yes & $248(69.7)$ \\
\hline $\begin{array}{l}\text { Infant eat limited varie- } \\
\text { ty of specific Food }\end{array}$ \\
No & $270(75.8)$ \\
Yes & $86(24.2)$ \\
\hline
\end{tabular}

Table 4: Behavior of inadequate of feeding among the studied infants

\begin{tabular}{|l|l|}
\hline $\begin{array}{l}\text { Causes of inadequate of feeding } \\
\text { (food refuse) }\end{array}$ & No. (\%) \\
\hline Crying & $8(7)$ \\
\hline Refuse to open mouth & $21(19)$ \\
\hline $\begin{array}{l}\text { Not swallowing and accumulate } \\
\text { food in Mouth }\end{array}$ & $13(12)$ \\
\hline Push food away & $11(10)$ \\
\hline Gagging reflex & $20(18.5)$ \\
\hline Vomiting & $35(33.5)$ \\
\hline
\end{tabular}


The prevalence of respiratory illness in the complementary-fed infants was $49.2 \%$. The majority of them (76\%) were those who started $C F<4$ months (group 1 vs. group 2, $\mathrm{p}=0.001$ ), (group $2 \mathrm{vs}$. group $3, \mathrm{p}=0.003$ ), and (group 1 vs. group 3, $p=0.001$ ). The prevalence of atopic dermatitis in complementary-fed infants was $70.5 \%$. The majority of them (51.8\%) were those who started CF $<4$ months (group 1 vs. group 2, $\mathrm{p}=0.003$ ), group 2 vs. group 3, $p=0.001$ ), and (group 1 vs. group 3 , $p=0.001$ ). Mouth ulcer was seen in $37.6 \%$ of complementary-fed infants, the majority (74.6\%) of them was observed in infants who started CF < 4months, (group 1 vs. group 2, $\mathrm{p}=0.001$ ), (group $1 \mathrm{vs}$. group $2, \mathrm{p}=0.009$ ) and (group 1 vs. group 3, $p=0.001$ ). Vitamin D deficiency and pallor were observed in $30.3 \%$ of the studied infants, the majority (37\%) of them were those who started CF after 6 months, (group 1 vs. group 2, $p=0.001$ ), (group 2 vs. group 3, $\mathrm{p}=0.001$ ), and (group 1 vs. group 3, $\mathrm{p}=0.001)$ (Table7).

\section{Discussion}

Our results illustrated that $45.7 \%$ of infants were on breastfeeding, $12.7 \%$ on formula feeding, $32.2 \%$ on cow milk, and $9.3 \%$ on mixed feeding. Our results also revealed that $47.5 \%$ of mothers complementary fed their infants before 4months, while mothers who exclusively breastfeeding until 6months were $11.2 \%$, and mothers who complementary fed their infants $4-6$ months were $41.3 \%$ which is similar to Wenge et $\mathrm{al}^{(8)}$. Median age of introduction of solid food was 11 weeks. In another study carried out by Gad et al $^{(9)}$ in Ismailia city-Egypt on 377 infants, breast feeding infants were (80.1\%) but not exclusively. Mothers who started weaning before 6 months were $(65.8 \%)$ and weaning after 6 monthswas (21\%), while (13.2\%) was unknown. The results revealed that $22.2 \%$ of mothers began with yoghurt and cow milk which were different from Wenge et $\mathrm{al}^{(8)}$. Who found that commercially prepared cereals were the type of food started with at complementary feeding. Our results revealed the causes of early complementary feeding before 4months was: i) the community thoughts, working mothers, working mothers who spend long time in their work, to grow babies faster, high cost artificial formula and scanty breast milk.

Table 5: Causes of early complementary feeding before 4 months in studied infants

\begin{tabular}{|l|l|}
\hline Causes & $\mathrm{n}=169$ \\
\hline Scanty breast milk to compensate insufficient breast milk & $7(4)$ \\
\hline High cost artificial formula & $13(7.7)$ \\
\hline Working mothers & $45(27.3)$ \\
\hline Community thoughts (to grow rapidly and gain weight). & $40(23)$ \\
\hline Community thoughts (to prepare infants to eat ordinary food as grown-up kids). & $64(38)$ \\
\hline
\end{tabular}

Table 6: Relationship between age at starting complementary feeding and weight in studied infants

\begin{tabular}{|l|l|l|l|l|l|}
\hline \multirow{2}{*}{ Weight } & \multicolumn{3}{|c|}{ Age when introduced to solid food (in months) } & \multirow{2}{*}{ P-value } \\
\cline { 2 - 6 } & Total $\mathrm{n}=418$ & $<4$ months & $4-6$ months & $>6$ months & \\
\hline Normal Weight & $366(87.6 \%)$ & $146(40 \%)$ & $135(36.9 \%)$ & $23(6.3 \%)$ & \multirow{2}{*}{0.001} \\
\hline Over weight & $15(3.5 \%)$ & $10(66.7 \%)$ & $4(26.7 \%)$ & $1(6.6 \%)$ & \\
\hline Under weight & $37(8.9 \%)$ & $13(35.2 \%)$ & $8(21.6 \%)$ & $16(43.2 \%)$ & \\
\hline
\end{tabular}


Table 7: Frequency between age at starting complementary feeding and gastrointestinal illness, respiratory illness, atopic dermatitis, mouth ulcer and (vitamin D deficiency manifestations, pallor) in studied infants

\begin{tabular}{|c|c|c|c|}
\hline & \multicolumn{3}{|c|}{ Onset of complementary feeding } \\
\hline & $<4$ Group (1) & 4-6 Group (2) & $>6$ Group (3) \\
\hline $\begin{array}{l}\text { Gastro-intestinal illness } \\
\text { No }=126 \\
\text { Yes }=230 \\
\text { Total } \\
\text { Recurrence case } n=140 / 230(60.9 \%)\end{array}$ & $\begin{array}{l}49(38.9) \\
120(52.2) \\
169 \\
103(73.6 \%)\end{array}$ & $\begin{array}{l}66(52.4) \\
81(35.2) \\
147 \\
30(21.4 \%)\end{array}$ & $\begin{array}{l}11(8.7) \\
29(12.6) \\
40 \\
7(5 \%)\end{array}$ \\
\hline $\begin{array}{l}\text { Respiratory illnesses } \\
\text { No=181 } \\
\text { Yes }=175 \\
\text { Total } \\
\text { Recurrence case } n=114 / 175(65.1 \%)\end{array}$ & $\begin{array}{l}36(19.9 \%) \\
133(76 \%) \\
169 \\
102(89.4 \%)\end{array}$ & $\begin{array}{l}109(60.2 \%) \\
38(21.7 \%) \\
147 \\
10(8.8 \%)\end{array}$ & $\begin{array}{l}36(19.9 \%) \\
4(2.3 \%) \\
40 \\
2(1.8 \%)\end{array}$ \\
\hline $\begin{array}{l}\text { Atopic dermatitis } \\
\qquad \begin{array}{l}\text { No }=105 \\
\text { Yes }=251\end{array}\end{array}$ & $\begin{array}{l}39(37.2 \%) \\
130(51.8 \%)\end{array}$ & $\begin{array}{l}42(40 \%) \\
105(41.8 \%)\end{array}$ & $\begin{array}{l}24(22.8 \%) \\
16(6.4)\end{array}$ \\
\hline $\begin{array}{l}\text { Mouth ulcer } \\
\qquad \begin{array}{l}\text { No }=222 \\
\text { Yes }=134 \\
\text { Recurrence case } n=121 / 134(90.3 \%)\end{array}\end{array}$ & $\begin{array}{l}69(31.1 \%) \\
100(74.6 \%) \\
92(76 \%)\end{array}$ & $\begin{array}{l}121(54.5 \%) \\
26(19.4 \%) \\
26(21.6)\end{array}$ & $\begin{array}{l}32(14.4 \%) \\
8(6 \%) \\
3(2.4 \%)\end{array}$ \\
\hline $\begin{array}{l}\text { Vitamin D deficiency manifestations, pallor } \\
\qquad \begin{array}{l}\text { No }=248 \\
\text { Yes }=108\end{array}\end{array}$ & $\begin{array}{l}139(56 \%) \\
30(28 \%)\end{array}$ & $\begin{array}{l}109(44 \%) \\
38(35 \%)\end{array}$ & $\begin{array}{l}0(0 \%) \\
40(37 \%)\end{array}$ \\
\hline
\end{tabular}

However, according to Wenge et $\mathrm{al}^{(8)}$, the most common cause was mothers wish to reduce nights feeds in order to get a longer time to sleep. Wright et al $^{(10)}$ showed that the majority of mothers introduced solid food before 3 months due to their feelings that their babies were hungry or because the baby was not sleeping through the night. Our study revealed that $(69.7 \%)$ of the infants eat adequate amount of food, (30.3\%) eat inadequate amount, the causes of inadequate of feeding were: food refusal (30.3\%); of those $7 \%$ of the infants refuse feeding by crying, $19 \%$ by refusing to open their mouth, $12 \%$ by accumulating food in their mouth, $10 \%$ by pushing food away, $18.5 \%$ by gagging reflex and $33.5 \%$ by vomiting. In addition, $24.2 \%$ of infants eat limited variety of food while $75.8 \%$ eat unlimited variety of food. Our results showed that the incidence of faulty CF was (58.7\%), mothers who introduced complementary feeding before 4 months were (47.5\%), their infants were more exposed to gastrointestinal illness, respiratory symptoms, atopic dermatitis, and mouth ulcer, than infants who started 46 months, and after 6 months. infants started after 6 months were more exposed to underweight and manifestations of pallor and vitamin D deficiency. Gad et al ${ }^{(9)}$ showed that the prevalence of feeding problems in the studied infants was $28.1 \%$. Moreover, there was higher frequency of feeding disorders in infants weaned after 6 months. The most frequent type of feeding problems were eating small amounts of food (43.4\%), eating non-nutritional foods (33\%), and slow eating (15.1\%). Gastrointestinal illness was observed in $65 \%$, of infants; more than half of them (52.2\%) were those who started complementary feeding before 4 months of age as reported previously ${ }^{(11)}$. The 
prevalence of respiratory illness in the complementary-fed infants was (49.2\%). The majority of infants who started CF $<4$ months was( $76 \%$ )of infants having respiratory illness. Similarly to Kramer et $\mathrm{al}^{(12)}$ The prevalence atopic dermatitis was $(70.5 \%)$ of the studied complementary fed infants, the majority of infants who started $\mathrm{CF}<4$ months was $(51.8 \%)$. Similarly to Zutavern et al ${ }^{(13)}$ The prevalence of mouth ulcer was $37.6 \%$ of studied complementary fed infants, the majority of infants who started $\mathrm{CF}<4$ months was $(74.6 \%)$. The prevalence of (vitamin D deficiency, pallor) was $30.3 \%$ of studied infants, the majority of infants who started CF after 6 months was (37\%). Similar results were concluded by Mary et al, who conducted their research in Mexico and reported that exclusive breastfeeding after 6 months of age, was associated with increased risk of anemia at 9 months $^{(2)}$ The prevalence of studied infants who were underweight was (8.9\%) of total population. The majority of infants were complementary fed after 6 months was (43.2\%). The prevalence of studied infants who were overweight was (3.5\%). The majority of infants were complementary fed before 4 months (66.7\%), this is in accordance with the results published by Wenge et $\mathrm{al}^{(8)}$.

\section{Conclusion}

Introduction of food before 4 months of age lead to significant high incidence and more recurrent attacks of gastrointestinal illness, eczema, respiratory illness, mouth ulcer, malnutrition and higher incidence of overweight. Introduction of food 46 months of age lead to less incidence of gastrointestinal and respiratory illness, atopic dermatitis, mouth ulcer.
Introduction of food after 6 months of age result in significance risk of underweight and vitamin $D$ deficiency and pallor manifestation.

\section{References}

1. Gartner LM, Morton J, Lawrence RA, Naylor AJ, O'Hare D, Schanler RJ, Eidelman Al; American Academy of Pediatrics Section on Breastfeeding. 2496 "Breastfeeding and the use of human milk. Pediatrics 2005; 115 (2): 496-506.

2. Fewtrell MS, Morgan JB, Duggan C, Gunnlaugsson G, Hibberd PL, Lucas A, Kleinman RE. Optimal duration of exclusive breastfeeding: what is the evidence to support current recommendations?. Am J Clin Nutr 2007; 85 (2):635S-638S.

3. Kleinman RE. Complementary feeding and later health.pediatrics.2000;106 (5):1287.

4. Kimmons JE, Dewey KG, Haque E, Chakraborty J, Osendarp SJ, Brown $\mathrm{KH}$. Behavior-change trials to assess the feasibility of improving complementary feeding practices and micronutrient intake of infants in rural Bangladesh. Food Nutr Bull 2004; 25(3):228-238.

5. Kull I, Bohme M,Wahlgren CF,Nordvall L,Pershagen G,Wickman M. Breast-feeding reduces the risk for childhood eczema.J Allergy Cin Immunol 2005;116 (3):657-661.

6. Dobson AJ. Calculating sample size, 'Trans Menziez Foundation 1984, 7:7579.

7. Forsyth JS, Ogston S, Clark A, Florey $C D$, Howie PW. Relation between early Introduction of solid food to infants and their weight and illnesses during the first two years of life.BMJ 1993; 306 (6892): 1572-1576.

8. Weng SF, Redsell SA, Swift JA, Yang $M$, Glazebrook CP. Systematic review and meta- analyses of risk factors for childhood overweight identifiable 
during infancy. Arch Dis Child 2012; 97 (12) :1019-1026.

9. Gad S.S.,Elkalioby M.,Nabil M. Feeding problems among Egyptian infants in Ismailia city. Abstract in SCUMJ suppl. (2), 2013.

10. Wright CM, Parkinson N,Drewett RF. Why are babies weaned early? Data from a prospective population based cohort study. Arch Dis Child 2004; 89(9):813-816.

11. Lamberti LM, Fischer Walker $C L$, Noiman A,Victora C, Black RE. Breastfeeding and the risk for diarrhea morbidity and mortality .BMC public health 2011; 11 (suppl 3):S15.

12. Kramer MS, Kakuma R. optimal duration of exclusive breastfeeding. Cochrane Database Syst Rev 2012, issue 8.

13. Zutavern A, Brockow I, Schaaf B, Bolte G, Von Berg AV, Diez U, Borte $M$, Herbarth $\mathrm{O}$, Wichmann $\mathrm{HE}$, Heinrich J. Timing of Solid Food Introduction in relation to Atopic Dermatitis and Atopic Sensitization: Results From a Prospective Birth Cohort Study. Pediatrics 2006;117 (2); 401-411. 